This item was submitted to Loughborough's Research Repository by the author.

Items in Figshare are protected by copyright, with all rights reserved, unless otherwise indicated.

\title{
The effects of water on an on-body monopole diversity antenna pair at
} $1800 \mathrm{MHz}$

PLEASE CITE THE PUBLISHED VERSION

http://dx.doi.org/10.1109/LAPC.2016.7807542

PUBLISHER

(C) IEEE

VERSION

AM (Accepted Manuscript)

LICENCE

CC BY-NC-ND 4.0

REPOSITORY RECORD

Al-Saffar, Dina A.H., Muhammad I. Khattak, and R.M. Edwards. 2019. "The Effects of Water on an On-body Monopole Diversity Antenna Pair at 1800mhz”. figshare. https://hdl.handle.net/2134/23550. 


\section{The Effects of Water on an On-body Monopole Diversity Antenna Pair at $1800 \mathrm{MHz}$}

\author{
Dina Al-Saffar \\ ${ }^{1}$ Wolfson School, Electronic Engineering, \\ Loughborough, Leicestershire, \\ England, UK \\ ${ }^{2}$ University of Technology, Baghdad, Iraq, \\ D.Al-Saffar@lboro.ac.uk \\ M. I. Khattak \\ Electrical Engineering Department, \\ University of Engineering and Technology \\ Peshawar, Pakistan. \\ M.I.Khattak@uetpeshawar.edu.pk
}

\author{
R. M. Edwards \\ Wolfson School, Electronic Engineering, \\ Loughborough, Leicestershire, \\ England, UK \\ R.M.Edwards@lboro.ac.uk
}

\begin{abstract}
This paper presents the effect of water on a pair of $1.8 \mathrm{GHz}$ on-body diversity monopole antennas mounted on the forearm of a sitting male static volunteer. Application of a water layer to the forearm was seen to both reduce efficiency and increase directivity leading to a slight overall increase in gain. Increased gain was shown to increase antenna correlation thereby reducing diversity gain in the antenna pair.
\end{abstract}

Keywords - Human body communication; wet and dry cloths; Diversity.

\section{INTRODUCTION}

Antennas close to the body suffer several perturbations to quality factor, efficiency and resonant frequency. These perturbations are caused by reflections from skin and absorption of energy. The body appears as a close lossy load to any body-mounted antenna system [1].

Energy absorbed by the body is essentially lost to the signal link budget. For reception on the body and to reduce fading a partial solution is to have multiple on-body receive antennas [2-4] so that diversity techniques can be used, for example selection combining (SC), maximal ratio combining (MRC) and equal gain combining (EGC) diversity, all on the body.

Previously researchers [5-8] have noted that water can be used to improve the link budget. This is due to increased reflection away from the body. Water has a higher permittivity $\left(\varepsilon_{r}=80\right.$ for $\left.1.8 \mathrm{GHz} 20^{\circ} \mathrm{C}\right)$ than skin $\left(\varepsilon_{r}=38.87\right.$ for $\left.1.8 \mathrm{GHz} 20^{\circ} \mathrm{C}\right)$ and if used in between the antenna and the skin a greater portion of the transmitted power is available at the receiver. In this work we have used a system with a single transmit and two receive antennas (SIMO). Diversity techniques such as SC, $\mathrm{MRC}$ and EGC make use of the fact that in general signals will fade independently in spatially separated channels and that with two or more channels available SNR can be improved over a single channel.

For antenna sets on the body it is desirable to have the antenna system as small as possible concluding to antennas close together. However, for maximal diversity, correlation between the antennas should be minimised. Water on the body is seen to both improve the channel and reduce diversity gain for two antennas placed on the forearm.

This paper presents results for a generic monopole diversity antenna set at $1800 \mathrm{MHz}$ GSM band of the type used in [7] and considers if combining techniques are useful for onbody communications systems that are wet.

\section{PROCEDURE FOR MEASUREMENTS}

Experiments took place in a laboratory of the $5 \mathrm{G}$ Research Centre (5GRC) at Loughborough University and were designed to examine the effect of wet human clothing on propagation in the two diversity channels. The experimental layout is shown in Fig.1. The system consisted of two National Instruments USRP-2950Rs used as a transmitter and receiver. These units were sited on wooden tables and synchronized using a cable. Two quarter-wave monopoles antennas designed for $1.8 \mathrm{GHz}$ and described in [7] were attached to the volunteer's forearm and driven as a diversity receive pair by one of the NI-USRPs. Note that the USRPs are capable of implementing MIMO but only SIMO system was used here.

LabVIEW was used in the host computer to generate and receive waveforms. A $7 \mathrm{dBi}$ used on the Tx side. The distance between midpoint of the Rx antenna set and the Tx horn phase centre was approximately $2.5 \mathrm{~m}$. This can reasonably be considered to be in the far field of the system. The distance between the two antennas on the arm was $0.25 \mathrm{~m}$. Care was taken to ensure that the antennas on the arm were parallel and perpendicular to the floor. The horn antenna was placed with its main beam perpendicular to a line between the two monopoles. The distance between the floor and the ground plane of the $\mathrm{Rx}$ antennas was $0.6 \mathrm{~m}$. This volunteer was an adult male of height $1.75 \mathrm{~m}$ and mass $75 \mathrm{~kg}$, wearing a pure cotton shirt and sitting on a chair with wooden arm. The arms of the volunteer were therefore supported and relatively static during the measurement period as shown in Fig. 2. 


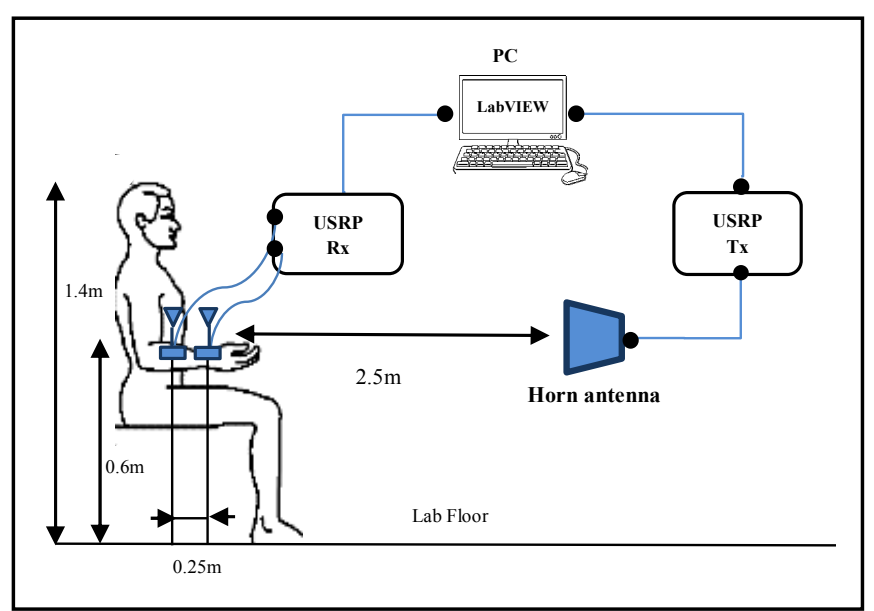

Fig.1 The experimental system using two software defined radios, two monopoles, a horn antenna, a PC running LabVIEW.

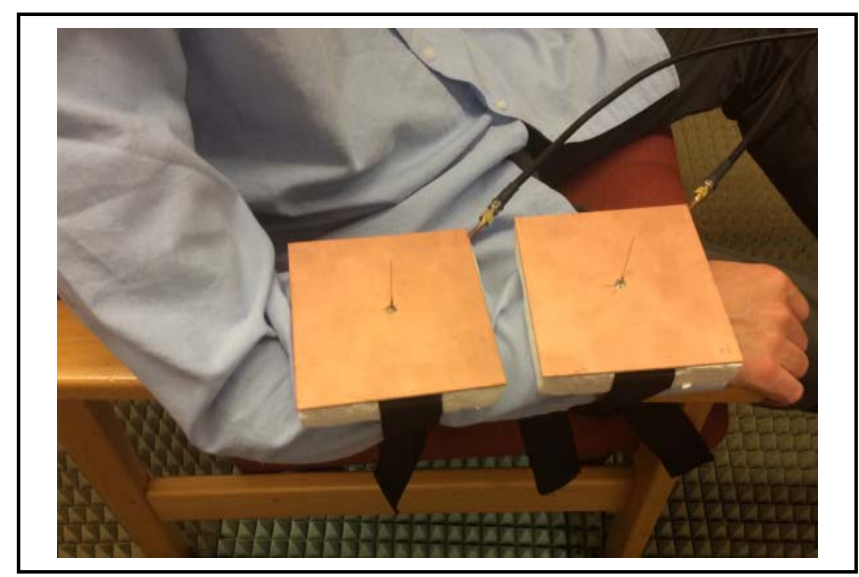

Fig.2 A two generic $1 / 4$ wave monopole antenna diversity set parallel and $0.25 \mathrm{~m}$ apart. Antennas as described in [7] spaced $0.2 \mathrm{~m}$ above the forearm

Measurements were taken for two scenarios, one with a dry sleeve and one with wet sleeve. A plant sprayer was used to wet the shirt of the volunteer in an area below and between both antennas to a point where the cotton was saturated but not dripping. The amount of water used was approximately $200 \mathrm{~mL}$. The groundplane is held above the plane of the arm by a spacer [7] and was not wet. Only the top side of the forearm was sprayed. Each set of measurements lasted for 5 milliseconds and contained approximately 5000 samples. The date rate was set to $125 \mathrm{k}$ symbols/second using 8QAM.

\section{RESULTS}

The received signal its mean power with and without wetting are shown in Fig.3. Both channels were similar and therefore only the results for the right hand channel (antenna farthest away from the chest) are shown here. The results show a power gain in the mean of $1 \mathrm{~dB}$ due to wetting of the arm. To establish if the effect was more significant in the near field of the Rx antennas or elsewhere in the channel the measurements were repeated with the lab floor in proximity to the chair covered in microwave absorber. In this location the microwave absorber will generally absorb ground reflected energy and if the water effect is dominated by better coupling of the receive diversity antenna set with the floor then the diversity gain will be changed significantly.

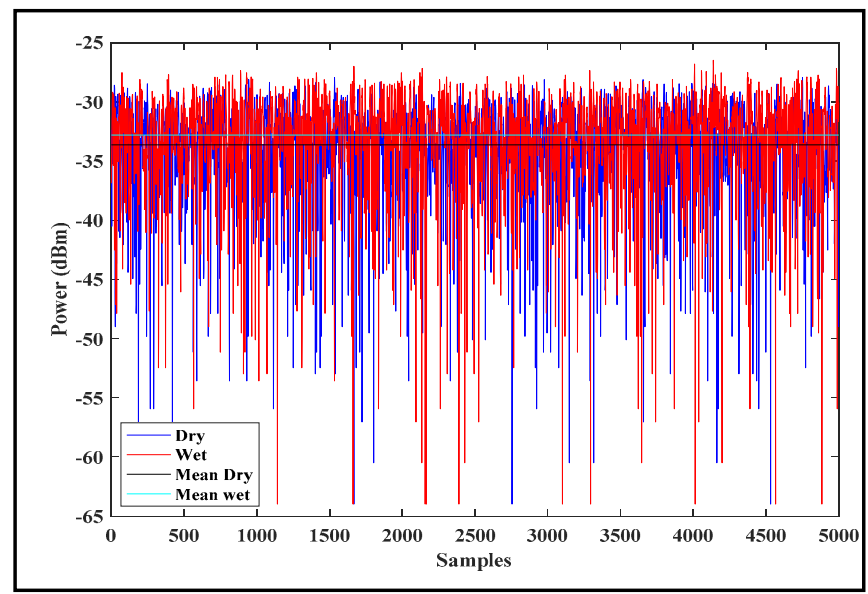

Fig.3 Power received for one monopole antenna with wet and dry sleeve without absorber on the floor.

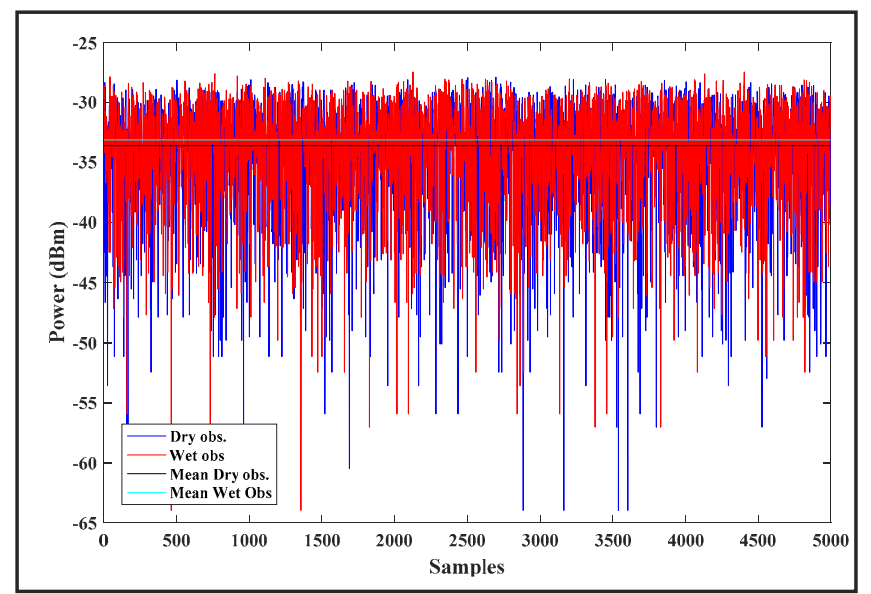

Fig.4 Power received for one monopole antenna with wet and dry sleeve with absorber on the floor.

Use of the absorber reduced the power at the received antennas by $4 \mathrm{~dB}$. However, there was still an improvement in diversity gain of approximately $2 \mathrm{~dB}$ regardless of whether the absorber on the ground was there or not. This concludes to the effect existing mainly locally to the receive antenna set supporting a hypothesis that the gains are due to increased reflection from the arms surface due to the higher permittivity of water.

\section{A. Simulations of an Antenna on the forearm}

To study the effects of water on the mutual coupling of the diversity antenna set a five layered model was made using CST 3D simulation software. The simulated human forearm model contained layers of, Dry skin, wet skin, fat, muscle and bone. The properties of human body tissues can be found on the website of Federal Communication Commission and are also given in CST Microstripes. The dimensions of the human forearm were approximated to an average human male and had a length of $300 \mathrm{~mm}$ with a radius of $45 \mathrm{~mm}$, which contributed 
to a circumference of approximately $280 \mathrm{~mm}$. The model with quarter-wave monopoles is shown in Fig. 5

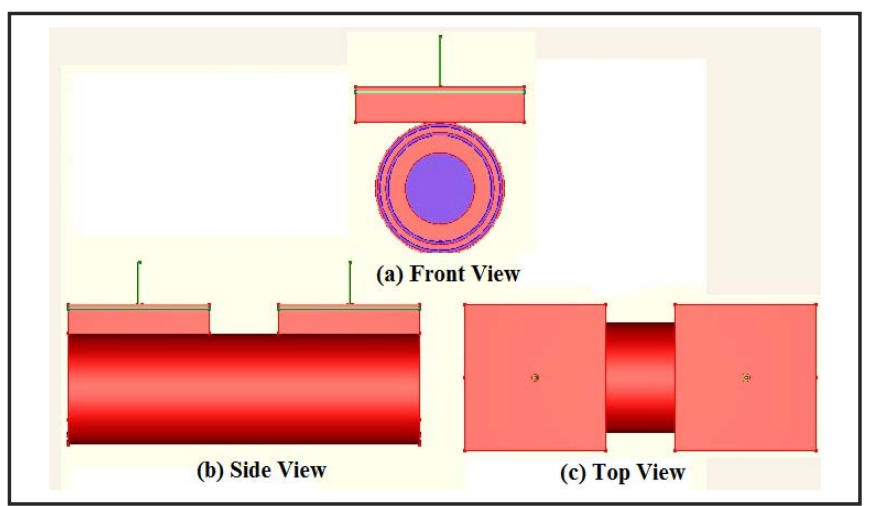

Fig.5 5-layer Arm Phantom (Dry skin, Wet skin, Fat, Muscle and Bone) of human male forearm with antennas

Details of the layers used are:- Dry skin $2 \mathrm{~mm}$, Wet skin $4 \mathrm{~mm}$, Fat $2 \mathrm{~mm}$, Muscle $12 \mathrm{~mm}$ and Bone $25 \mathrm{~mm}$ for dry conditions and to simulate wetness a $1 \mathrm{~mm}$ thick layer of water was also introduced in between polystyrene and dry skin layer of the model. The antennas used are discussed in [7]

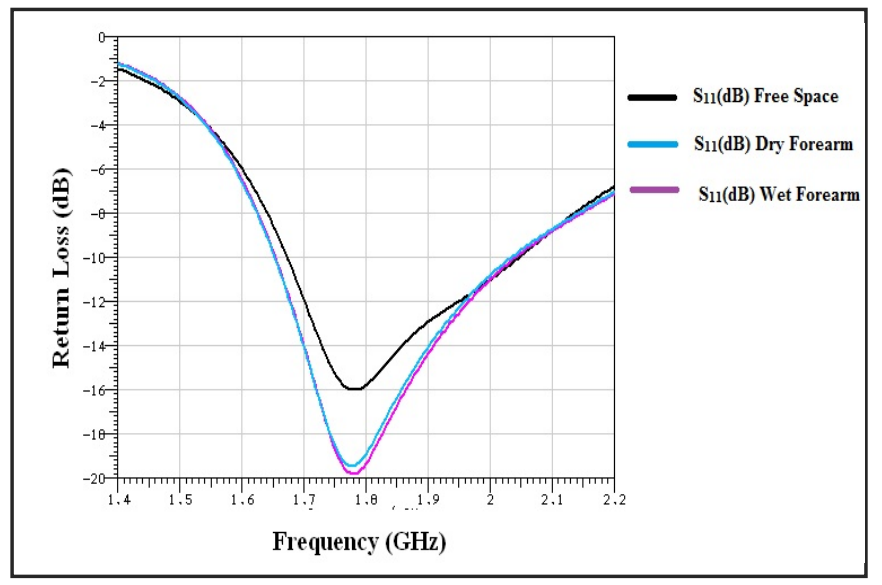

Fig.6 Simulated Return Loss $(\mathrm{S} 11(\mathrm{~dB}))$ of the Monopole at $1.8 \mathrm{GHz}$ in Free Space and on Wet and on a Dry Human Forearm.

The modelled return loss of the monopole antenna in free space and on a dry and a wet human forearm is shown in Fig.6. It was seen in that use of the monopoles on the arm improved the return loss by over $5 \mathrm{dBs}$ and that a water layer improved it again by a further $0.5 \mathrm{dBs}$. In the model S21 between the antennas improved by approximately $2.5 \mathrm{dBs}$. Water on the arm was not seen to significantly affect the coupling between the antennas.

Modelled results showed that the antenna directivity and gain have been improved from 3.34 to $3.76 \mathrm{dBi}$ and 3.22 to $3.48 \mathrm{dBi}$ respectively but the antenna efficiency is reduced from $97.3 \%$ to $93.7 \%$. This trend suggests that the body gives us better directivity but increased losses, so things are better in the main beam but overall they are worse by a little.

\section{B. Results for Antenna Diversity}

With reference to Fig. 7, the results for diversity with two monopoles show that water on the arm worsens diversity gain but that diversity in all cases with the forearm wet or dry yields improvements. The measured results of the three combining methods are shown in Table 1.

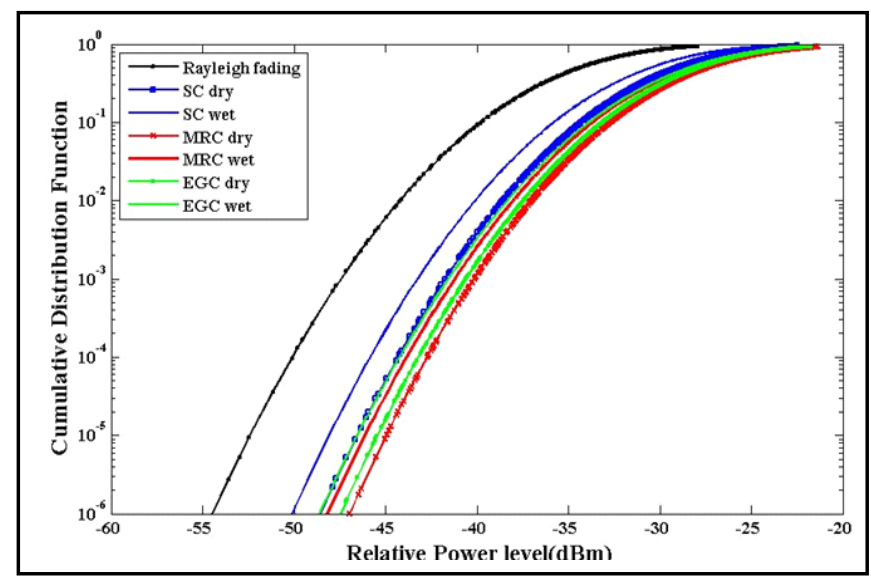

Fig.7 Selection, Maximal Ratio and Equal gain combining gain results with a wet and dry forearm.

Note that in Fig. 7 an analytical Rayleigh Fading Channel has been added as a benchmark for a single channel. In [4], more detailed description of the methods used in the measurements in form of cumulative density functions can be found.

TABLE I. RESULTS FOR WET AND DRY VOLUNTEER'S SLEEV WITHOUT OBSORBER .RESULTS IN TABLE 1 ARE IN dB ROUNDED TO 1 DECIMAL PLACE, AT $10^{-3}$ FOR CUMULATIVE DESTRIBUTION FUNCTION

\begin{tabular}{|c|c|c|c|}
\hline Set & $\boldsymbol{S C}$ & $\boldsymbol{E G C}$ & $\boldsymbol{M R C}$ \\
\hline Wet & -43.100 & -41.541 & -41.046 \\
\hline Dry & -41.528 & -40.592 & -40.118 \\
\hline
\end{tabular}

\section{CONCLUSIONS.}

In this paper we have shown the effects of water on a body worn diversity system. If water is present, the channel to each antenna is improved. In isolation a monopole of the type used here may benefit from being on the arm with increased gain in the main lobe but an overall reduction in efficiency. Water on the forearm has been shown to improve S21 between the diversity antennas thereby reducing diversity gain. Maximal ratio combining was seen to be the best of the three diversity techniques measured in both wet and dry scenarios.

A monopole above a ground plane has been shown to have vertical polarisation [9]. Horizontally polarised waves are considered less suitable for on-body communications because of their high attenuation in the skin at $1.8 \mathrm{GHz}$. However, for good isolation between the diversity antennas in a SIMO system, an antenna with horizontal polarisation may be a better choice and this is future work. In our research we have not yet used salt water that is more representative of perspiration. 


\section{REFERENCES}

[1] R. M. Edwards, "Wireless Body Area Network Channels," in LTEAdvanced and Next Generation Wireless Networks: Channel Modelling and Propagation, vol. 2012, John Wiley \& Sons, 2012, p. 568.

[2] S. L. Cotton and W. G. Scanlon, "An experimental investigation into the influence of user state and environment on fading characteristics in wireless body area networks at $2.45 \mathrm{GHz}$," in IEEE Transactions on Wireless Communications, vol. 8, no. 1, pp. 6-12, Jan. 2009.

[3] D. Al-Saffar, E. Habeeb, R. M. Edwards, O. Ojerinde, H. M. Alsabbagh and C. J. Panagamuwa, "Human effect on on-body selective combining at $2.4 \mathrm{GHz}, "$ Antennas and Propagation Conference (LAPC), 2014 Loughborough, Loughborough, 2014, pp. 381-384.

[4] D. Al-Saffar, R. M. Edwards, O. Ojerinde, C. J. Panagamuwa and R. D. Seager, "Human effect on twin antenna On-body for three diversity techniques at $2.4 \mathrm{GHz}, 2015$ 9th European Conference on Antennas and Propagation (EuCAP), Lisbon, 2015, pp. 1-4.

[5] D. J. Y. Lee and W. C. Y. Lee, "Water enhancement for macro and microcell models," Vehicular Technology Conference, 2000. IEEE-VTS Fall VTC 2000. 52nd, Boston, MA, 2000, pp. 818-821 vol.2.

[6] Khattak, M. I., R. M. Edwards, and J. Ma. "A study of perturbations due to antennas in close proximity with the human body and body simulating liquid filled phantoms at 1.8 GHz." Antennas \& Propagation Conference, 2009. LAPC 2009. Loughborough. IEEE, 2009.

[7] Khattak, M. I., et al. "A study of the on-body channel for a human male with wet and dry clothing." WWRF 21st Meeting, 13th-15th October. 2008.

[8] D. Al-Saffar, R. M. Edwards, "A software defined radio comparison of received power with quadrature amplitude modulation and phase modulation schemes with and without a human," 2016 10th European Conference on Antennas and Propagation (EuCAP), Davos, Switzerland, 2016, pp. 1-4.

[9] R. G. Vaughan, A. Lea, Ping Hui and J. Ollikainen, "Theory of propagation for direct on-body wireless sensor communications," Antennas and Propagation for Body-Centric Wireless Communications, 2009 2nd IET Seminar on, London, 2009, pp. 1-5. 